\title{
REFERENCES
}

Baumann, E. J. \& Metzger, N. (1949). Proc. Soc. exp. Biol., $N . Y ., 70,536$.

Brodie, B. B. \& Friedman, M. M. (1937). J. biol. Chem. 120, 511.

Crandall, L. A. \& Anderson, M. X. (1934). Amer. J. digest. Dis. 1, 126.

Leblond, C. P. (1948). Advanc. Biol. med. Physics, 1, 353.
McClendon, J. F. \& Bratton, A. C. (1938). J. biol. Chem. 123, 699.

Shrewsbury, C. L., Hatfield, J. D., Doyle, L. P. \& Andrews, F. N. (1944). Bull. Purdue Agric. Exp. Sta. no. 499.

Stanley, M. M. \& Astwood, E. B. (1948). Endocrinology, 42, 107.

\section{Biochemistry of the Wood-rotting Fungi}

\section{VOLATILE METABOLIC PRODUCTS OF SPECIES OF ENDOCONIDIOPHORA}

\author{
By J. H. BIRKINSHAW AND E. N. MORGAN \\ Department of Biochemistry, London School of Hygiene and Tropical Medicine, \\ University of London
}

(Received 30 December 1949)

The substances responsible for the characteristic odours of the fungi Lentinus lepideus Fr. and Trametes suaveolens (Linn.) Fr. have been isolated and characterized (Birkinshaw \& Findlay, 1940; Birkinshaw, Bracken \& Findlay, 1944). The odours are due mainly to aromatic esters, amongst which the methyl esters of $p$-methoxycinnamic, cinnamic, and anisic acids were identified in the products of Lentinuslepideus, and methyl anisate in the products of Trametes suaveolens. The latter fungus also produced anisaldehyde which was a contributor to the odour.

This work has now been extended to an investigation of the odoriferous products of species of Endoconidiophora. Some of the products isolated were briefly reported (Morgan, 1948) whilst the investigation was in progress; a complete account of this work forms the subject of the present communication. Endoconidiophora is a genus established by Münch to include the species of Ceratostomella which produce secondary spores in an endogenous manner (i.e. from within the terminal cell and not by abscission of the ends of the hyphae). It includes a number of species important as a cause of 'blue stain' or 'sap stain' in logs and sawn timber. Endoconidiophora coerulescens is an important cause of staining in sap wood in Europe, and according to Davidson (1944) $E$. virescens is one of the principal fungi causing stain in hardwoods in the southern United States. $E$. fimbriata is said to be of little importance as a stainer of timber.

The bluish tinge produced by these fungi is not due to a pigment, but is an optical effect caused by the scattering of light rays striking the very fine dark hyphae. The bluish colour of diluted milk is produced in a similar way. Whilst sap stain has little effect on the mechanical properties of the commoner European soft woods, it may be more serious in soft tropical woods.

When some Endoconidiophora species are grown under laboratory conditions a pleasant fruity odour is evolved. Davidson (1944) refers to the banana-oil (amyl acetate) odour as a characteristic of $E$. coerulescens. He describes the odour of $E$. virescens as musty and penetrating. $E$. coerulescens was selected, from the species made available to us, as yielding the strongest odour, and was cultured in quantity on a liquid malt medium.

After a few days the odour permeated the incubator room. After harvesting, the fungal mycelium and culture fluid were subjected to steam distillation. The steam-volatile products were then distilled. Two main fractions were obtained. The lower boiling fraction was found to consist of isobutyl acetate $\left(\mathrm{HCMe}_{2} \cdot \mathrm{CH}_{2} \cdot \mathrm{O} \cdot \mathrm{CO} \cdot \mathrm{CH}_{3}\right)$; the higher fraction contained methylheptenone (2-methylhept-2-en-6-one) and a mixture of methylheptenols (2-methylhept-2en-6-ol) in which the dextrorotatory isomer and the racemic form were detected and characterized as allophanates. Since (+)-methylheptenol has been shown by Levene \& Haller (1929) to be configurationally related to $(+)$-lactic acid, which is now denoted as L-lactic acid, the two methylheptenols isolated are correctly described as L-2-methylhept2-en-6-ol and the corresponding DL-compound.

Two other species of Endoconidiophora were readily available and were examined by way of comparison. E. virescens, which gave a less pronounced odour than $E$. coerulescens, produced methylheptenone and L- and DL-methylheptenol, but no isobutyl acetate could be detected. None of these products was isolated from $E$. fimbriata, which 
also produced practically no odour. The amyl acetate odour referred to by Davidson (1944) as characteristic of $\boldsymbol{E}$. coerulescens is no doubt that of isobutyl acetate. The fact that this odour is not produced by $\boldsymbol{E}$. virescens, which is one of the reasons advanced by Davidson (1944) for separating $E$. virescens from $\boldsymbol{E}$. coerulescens as a distinct species, agrees with our failure to find isobutyl acetate in the volatile metabolic products of $E$. virescens.

The occurrence of isobutyl acetate in nature does not appear to have been previously recorded, but the alcoholic component, isobutanol, occurs in fusel oils and certain essential oils. It is found in Java citronella oil together with methylheptenone (Bohnsack, 1943). It occurs, esterified with angelic acid and with isobutyric acid, in Roman chamomile oil (Köbig, 1879).

Acetic acid is probably formed in traces by a number of fungi since many have been shown to yield small amounts of volatile acid, and one of its esters, ethyl acetate, is a product of the mould Penicillium digitatum (Birkinshaw, Charles \& Raistrick, 1931).

Methylheptenone is a constituent of various natural essential oils such as lemongrass oil, palmarosa oil, linaloe oil, cacao oil and verbena oil. An optically active form of methylheptenol has been recorded in linaloe oil.

Methylheptenone is readily convertible by chemical reduction to the DL-methylheptenol and it seems likely that the fungus may achieve a similar reduction and that, under biological conditions, the two possible stereoisomerides might be formed in unequal amounts. This is in accordance with the detection of $\mathrm{L}$-methylheptenol in addition to the DLcompound as a product of Endoconidiophora species. The methylheptenol isolated from linaloe oil had a small negative rotation $\left([\alpha]_{D}-1 \cdot 57^{\circ}\right.$ : Schimmel \& Co., 1908); this indicates a slight preponderance of the $D$ - over the L-isomeride, since the value is much lower than that for the pure enantiomorphs.

The possibility that the synthesis of the alcohol by Endoconidiophora species precedes that of the ketone must not be overlooked, but if that were the case it might be expected that one stereoisomeride would be formed to the exclusion of the other.

It is of some interest to note that Neuberg \& Lewite (1918) attempted the phytochemical reduction of various ketones by adding them to a yeast fermentation, and found that, of the ketones examined, only methylheptenone was reduced in these conditions. In two experiments apparently differing only in the time of incubation the optical rotation of the product was of opposite sign in the two cases. After 2 months' incubation the methylheptenol had $[\alpha]-6 \cdot 50^{\circ}$, after 3 months' incubation, $[\alpha]+2 \cdot 06^{\circ}$. Here again the products must have been mixtures of the D-and L-methylheptenols in unequal amounts.
In later work (Neuberg \& Nord, 1919; Akamatsu, 1923) various aliphatic, aromatic and cyclic ketones were shown to be susceptible to phytochemical reduction by yeast, with production of optically active secondary alcohols.

The association of isobutanol (or its esters), methylheptenone and methylheptenol as metabolic products of both green plants and of fungi and their obvious chemical relationship suggests that the mechanism of the synthesis may be similar in the two cases.

\section{EXPERIMENTAL}

Cultures. The cultures were obtained through the courtesy of Dr W. P. K. Findlay from the Forest Products Research Laboratory, Princes Risborough (F.P.R.L.).

1. E. coerulescens Münch-F.P.R.L. No. S87-isolated by Rennerfelt in Sweden.

2. $E$. virescens Davidson-F.P.R.L. No. S81-U.S. Department of Agriculture, Division of Forest Pathology, No. 94255.

3. E. fimbriata (Ell. \& Hals.) Davidson-F.P.R.L. No. S90-isolated by Davidson from brown-stained beech, received from Centraalbureau voor Schimmelcultures.

Preparation of inoculum. The cultures for inoculation were grown on a sterile Norway spruce sawdust medium containing $10 \%$ of an accelerator consisting of $50 \%$ maize meal, 30\% bone meal and $20 \%$ A.R. starch (Badcock, 1941). The sawdust (33.3 g.) and accelerator (3.7 g.) were well mixed and moistened with distilled water $(75 \mathrm{ml}$.). The moist mixture was lightly packed into large boiling tubes which were sterilized by autoclaving.

Incubation of the inoculated sawdust medium at $24^{\circ}$ resulted in a fairly rapid development of the fungus throughout the medium. The progress of the infection could be followed visibly in the cases of $E$. coerulescens and $E$. virescens owing to the very dark colour of the developing hyphae. For inoculation of the culture medium about $1 \mathrm{~g}$. of the infected sawdust was added to each flask.

Medium and conditions of culture. The culture solution employed consisted of $4 \%(w / v)$ of Vimaltol in distilled water (Vimaltol is a proprietary malt extract with addition of vitamins $A, B_{1}, D$, niacin and iron). The medium was. distributed in conical flasks of 1 l. capacity, $350 \mathrm{ml}$. to each flask. The flasks were plugged with cotton wool, autoclaved at $110^{\circ}$, inoculated with the infected sawdust and incubated at $24^{\circ}$.

\section{Products From ENDOCONIDIOPHORA COERULESCENS}

After 4-5 days a complete mycelium extended over the surface of the medium and a pleasant ester-like odour was observed which in the later stages of growth permeated the incubator room. After 15 days' incubation, when the fungus was harvested, the fragile mycelium had a mottled steelgrey to black upper surface with a black reverse. The total contents of the flasks were then subjected to steam distillation. The distillate contained colourless globules of oil floating on the surface of the water. The oil was collected by extraction with ether and careful removal of the solvent. Since the culture fluid inoculated with another species ( $E$. fimbriata) gave only a trace of steam-volatile material, the oil obtained with $E$. coerulescens cannot have been pro- 
duced from the medium alone. The extracted oil from ninety-two flasks was subjected to distillation and gave the following fractions: fraction I, 0.65 g., b.p. $110-120^{\circ}$ $764 \mathrm{~mm}$.; fraction II, $4.48 \mathrm{~g}$., b.p. $173-176^{\circ} / 764 \mathrm{~mm}$., $n_{D}^{20^{\circ}} 1.443$; undistilled residue $0.58 \mathrm{~g}$.

\section{Treatment of fraction I}

Fraction I was a colourless mobile ofl with a pleasant ester-like smell. The oil ( $0 \cdot 3865 \mathrm{~g}$.) was hydrolysed by refluxing on a boiling-water bath with $10 \mathrm{ml}$. of $\mathrm{N}-\mathrm{NaOH}$ for $2 \mathrm{hr}$. The reaction mixture was extracted with ether. The residue on removal of the ether was an oil $(0 \cdot 122 \mathrm{~g}$.) with an odour reminiscent of isobutanol. Its identity was confirmed by heating it with 3:5-dinitrobenzoyl chloride $(0.250$ g.) in benzene $(5 \mathrm{ml}$.) containing a few drops of pyridine for $0.5 \mathrm{hr}$. on a water bath. The cooled reaction mixture was diluted with ether, washed with dilute $\mathrm{NaOH}$, dilute $\mathrm{HCl}$ and water, and the solvent was removed in vaeuo. The residue $(0 \cdot 152 \mathrm{~g}$.) after recrystallization from light petroleum gave colourless needles (95 mg.), m.p. $86^{\circ}$, undepressed on admixture with the authentic 3:5-dinitrobenzoate, m.p. $86-87^{\circ}$, of isobutanol. (Found: C, 49.1; $\mathrm{H}, 4 \cdot 5 ; \mathrm{N}, 10 \cdot 2$. Calc. for $\mathrm{C}_{11} \mathrm{H}_{12} \mathrm{O}_{6} \mathrm{~N}_{2}: \mathrm{C}, 49 \cdot 3 ; \mathrm{H}, 4.5$; $\mathrm{N}, 10.4 \%$.) The 3:5-dinitrobenzoates of $n$-butanol and of sec.-butanol have m.p.'s $64^{\circ}$ and $75^{\circ}$ respectively. The m.p. of the mixture of the dinitrobenzoate of the latter alcohol with that of the metabolic product showed marked depression.

The volatile acid present as the $\mathrm{Na}$ salt in the etherextracted alkaline layer was obtained after acidification with $\mathrm{N}-\mathrm{H}_{2} \mathrm{SO}_{4}$ by repeated distillation to low volume with addition of successive quantities of distilled water. The total volatile acid in the aqueous distillate required $25.75 \mathrm{ml}$. of $0 \cdot 1 \mathrm{~N}-\mathrm{NaOH}$ for neutralization to phenolphthalein. The concentrated aqueous solution of the $\mathrm{Na}$ salt $(4 \mathrm{ml}$.) was refluxed with ethanol $(8 \mathrm{ml}$.) and $p$-bromophenacyl bromide $(0.70 \mathrm{~g}$.) for $75 \mathrm{~min}$. The reaction mixture deposited on cooling a small amount of unchanged reagent. This was removed by filtration, and the filtrate was diluted with water to give crystals, which after recrystallization from light petroleum had m.p. 84-85 $(0 \cdot 10 \mathrm{~g}$.) and showed no depression on admixture with authentic $p$-bromophenacyl acetate of m.p. $85^{\circ}$. (Found: C, 46.7; H, 3.3; Br, 31.0. Calc. for $\mathrm{C}_{10} \mathrm{H}_{2} \mathrm{O}_{3} \mathrm{Br} ; \mathrm{C}, 46 \cdot 7 ; \mathrm{H}, 3 \cdot 5, \mathrm{Br}, 31 \cdot 1 \%$.)

Fraction I therefore consisted substantially of isobutyl acetate. Further confirmation was obtained by determination of the apparent equivalent (after hydrolysis) of a sample which had been twice distilled at $110-120^{\circ} / 766 \mathrm{~mm}$. in a microstill. The ester $(0 \cdot 3517 \mathrm{~g}$.) required $2 \cdot 80 \mathrm{ml}$. of $\mathrm{N}-\mathrm{NaOH}$ for complete hydrolysis giving an apparent equivalent of 125.5. (Calc. for isobutyl acetate, 116.) The value obtained would correspond with isobutyl acetate of about $93 \%$ purity.

\section{Derivatives}

\section{Treatment of fraction II}

(a) 2:4-Dinitrophenylhydrazone. Fraction II (0.203 g.) was dissolved in ethanol (3 ml.) and treated with a solution ( $200 \mathrm{ml} ., 0.4 \%$ ) of 2:4-dinitrophenylhydrazine in approx. $2 \mathrm{~N}-\mathrm{HCl}$ (Brady \& Elsmie, 1926). This reagent is hereinafter referred to as Brady's reagent. The orange-yellow turbid mixture slowly flocculated and was filtered after keeping overnight. The orange-coloured product $(0 \cdot 200$ g.) was recrystallized from light petroleum (b.p. 40-60 $0^{\circ}$ giving orange needles of m.p. $87^{\circ}$. (Found: C, 54.9; H, 6.0; N, 18.2. Calc. for $\mathrm{C}_{14} \mathrm{H}_{18} \mathrm{O}_{4} \mathrm{~N}_{4}$. C, 54.9; $\mathrm{H}, 5.9 ; \mathrm{N}, 18.3 \%$.) This gave a pure red colour with ethanolic $\mathrm{NaOH}$ and was evidently the hydrazone of a carbonyl compound, $\mathrm{C}_{8} \mathrm{H}_{14} \mathrm{O}$. With the 2:4-dinitrophenylhydrazone of naturally occurring methylheptenone (m.p. $87^{\circ}$ ) prepared similarly it gave no depression in m.p. on admixture. Allen (1930) recorded a m.p. of $81^{\circ}$ for this derivative, but gave no analytical figures. Assuming complete precipitation of the derivative, the crude yield would correspond to about $40 \%$ of methylheptenone in fraction II.

(b) Semicarbazone. Fraction II (0.230 g.) was heated on the water bath for $1 \mathrm{hr}$. with semicarbazide hydrochloride $(0.50 \mathrm{~g}$.) and $\mathrm{Na}$ acetate $(1 \mathrm{~g}$.$) , both dissolved in the mini-$ mum amount of water. Ethanol $(2 \mathrm{ml}$.) was added to give a clear reaction mixture. On cooling colourless flattened needles were obtained, which after recrystallization from light petroleum (b.p. $80-100^{\circ}$ ), had m.p. $135-136^{\circ}$; yield $0 \cdot 10$ g. (Found: C, 59.2; H, 9.1; N, 21.8. Calc. for $\mathrm{C}_{9} \mathrm{H}_{17} \mathrm{ON}_{3} ; \mathrm{C}, 59.0 ; \mathrm{H}, 9.4 ; \mathrm{N}, 22.9 \%$.) This would be derived from a carbonyl compound, $\mathrm{C}_{8} \mathrm{H}_{14} \mathrm{O}$. The m.p. was not depressed on admixture with the authentic semicarbazone of methylheptenone, m.p. $135-136^{\circ}$. This m.p. agrees with that found by Hey \& Morris (1948). A portion of fraction II therefore consists of 2-methylhept-2-en-6-one.

Fraction II therefore consisted to the extent of some $40 \%$ of methylheptenone, the remainder being presumably nonketonic in nature and containing a substance or substances of similar b.p. and possessing an asymmetric carbon atom since the fraction was found to be optically active. It was considered that the most likely substance having these properties was the corresponding methylheptenol (or methylheptanol). A number of reagents likely to give crystalline products with the presumed hydroxyl group were tried: namely, 3:5-dinitrobenzoyl chloride, phenylisocyanate, $\alpha$-naphthylisocyanate; conversion to the acid phthalate and preparation of crystalline esters was also attempted, but only non-crystalline oils were produced; success was finally attained by the use of cyanic acid to yield allophanates.

(c) Allophanates. Cyanic acid obtained by heating dry cyanuric acid (l g.) distributed along a horizontal Pyrex tube $(10 \times 1 \mathrm{~cm}$.) bent downward at the exit, was driven by a slow current of dry $\mathrm{CO}_{2}$ into fraction II ( $0 \cdot 50 \mathrm{~g}$.) contained in a small bulb supported in a freezing mixture. When all the cyanuric acid had been decomposed, the bulb was removed from the freezing mixture and gently agitated. Reaction took place with considerable rise in temperature and the mixture solidified. After some hours the reaction mixture was dissolved in warm ether and any cyanuric acid present removed by filtration. The residue on removal of the ether consisted of a white slightly sticky solid, smelling of the unattacked methylheptenone. Trituration of the product with the minimum volume of cold light petroleum (b.p. $40-60^{\circ}$ ) removed both the stickiness and the odour and gave a white powder, m.p. $80-95^{\circ}(0 \cdot 35$ g. $)$, which was recrystallized from $40 \%(\mathrm{v} / \mathrm{v})$ aqueous ethanol by warming and cooling to room temperature and gave mixed needle crystals $(0 \cdot 19 \mathrm{~g}$.$) of m.p. 115-123^{\circ}$.

The mother liquor, after chilling, deposited a homogeneous crop of crystalline tablets (38 mg.) of m.p. 102-103', which formed microcrystalline sheaves of needles, m.p. $103-104^{\circ}$, on recrystallization from light petroleum (b.p. $40-60^{\circ}$ ). This substance was optically inactive. Admixture with an authentic sample of DL-methylheptenyl allophanate 
of m.p. 103-104 ${ }^{\circ}$ gave no depression. Doeuvre (1929) records a m.p. of $99-100^{\circ}$ for the racemic allophanate.

The main fraction $(0 \cdot 19 \mathrm{~g}$.) on further purification showed a gradual rise in m.p. to a constant value. A final recrystallization from hot water gave material (35 mg.), of m.p. $136-137^{\circ},[\alpha]_{5461}^{21^{\circ}}+47^{\circ}$ in ethanol. (Found: $\mathrm{C}, 55.9 ; \mathrm{H}, 8.4$; $\mathrm{N}, 13 \cdot 1 . \mathrm{C}_{10} \mathrm{H}_{18} \mathrm{O}_{3} \mathrm{~N}_{2}$ requires $\mathrm{C}, 56 \cdot 0 ; \mathrm{H}, 8 \cdot 5 ; \mathrm{N}, 13 \cdot 1 \%$.) The m.p. was not depressed on admixture with the allophanate of synthetic L-methylheptenol, m.p. $137^{\circ}$. $[\alpha]_{5461}^{20^{\circ}}+47^{\circ}$ in ethanol $(c, 1 \cdot 06)$. The appearance and behaviour of the two allophanates on recrystallization was of diagnostic value. The racemic allophanate, m.p. 103-104, formed microcrystalline colourless needles which retained their shape on standing in water. In contrast, the dextrorotatory allophanate, m.p. $137^{\circ}$, formed microcrystalline feathery needles which appeared to have a slight blue tinge when viewed by reflected light. On standing in water they lost their crystalline form overnight and became completely gelatinous. When the substance was redissolved by heating, the needles were produced on cooling, eventually becoming gelatinous. The racemic form was slightly more soluble in both water and light petroleum.

No other allophanates were detected in the mother liquor.

Early clues as to the nature of the distillate fraction II which led to the identification of the substances present by means of suitable derivatives were afforded by ozonolysis and by the action of permanganate.

Ozonolysis. Fraction II $(0 \cdot 2370$ g. $)$ dissolved in $\mathrm{CHCl}_{3}$ $(20 \mathrm{ml}$.) and chilled in ice was treated with a current of ozonized $\mathrm{O}_{2}$ for $40 \mathrm{~min}$. The resulting ozonide was decomposed by shaking the $\mathrm{CHCl}_{3}$ solution with an equal volume of water at $55^{\circ}$ and separating the two layers.

The water layer was treated with Brady's reagent. The yellow precipitate $\left(40 \mathrm{mg}\right.$; m.p. $\left.190-205^{\circ}\right)$ recrystallized from pyridine gave microcrystalline needles of m.p. $227^{\circ}$.

The $\mathrm{CHCl}_{3}$ layer, after removal of solvent in vacuo, was treated with ethanol (3 ml.) and Brady's reagent (200 ml:). The product $(0.32 \mathrm{~g}$.) when recrystallized from pyridine, nitrobenzene, or xylene had m.p. $228-229^{\circ}(0 \cdot 10$ g.) identical with the dinitrophenylhydrazone obtained from the water layer. (Found: $\mathrm{C}, 44 \cdot 4 ; \mathrm{H}, 3 \cdot 5 ; \mathrm{N}, 24 \cdot 1$. Calc. for $\mathrm{C}_{17} \mathrm{H}_{16} \mathrm{O}_{8} \mathrm{~N}_{8}$ : $\mathrm{C}, 44.4 ; \mathrm{H}, 3.5 ; \mathrm{N}, 24.4 \%$.) The analysis indicates that the product is a bis-dinitrophenylhydrazone of $\mathrm{C}_{5} \mathrm{H}_{8} \mathrm{O}_{2}$, which would be expected to give a blue colour with ethanolic $\mathrm{KOH}$. This product however, when dissolved in methanol, gave a ruby-red colour on addition of a drop of $2 \mathrm{~N}-\mathrm{KOH}$. The bis-dinitrophenylhydrazone of levulaldehyde of the same m.p. as the product, prepared for comparison, gave an identical colour reaction and showed no depression in m.p. on mixing the two substances.

The aqueous filtrate obtained from the above derivative slowly deposited an orange-brown bis-dinitrophenylhydrazone, giving a blue colour with methanolic KOH. Recrystallization from nitrobenzene gave orange-brown needles of m.p. 302-304 ${ }^{\circ}$ (decomp.) undepressed by the corresponding derivative of methylglyoxal. (Found: $\mathrm{C}, 42.1 ; \mathrm{H}, 2.7 ; \mathrm{N}$, 27.5. Calc. for $\mathrm{C}_{15} \mathrm{H}_{12} \mathrm{O}_{8} \mathrm{~N}_{8}: \mathrm{C}, 41 \cdot 7 ; \mathrm{H}, 2 \cdot 8 ; \mathrm{N}, 25 \cdot 9 \%$.)

In the later stages of distillation of the $\mathrm{CHCl}_{3}$ from the decomposed ozonides a precipitate appeared in a trap containing Brady's reagent inserted in the vacuum line. This afforded a product which on recrystallization from ethanol formed yellow needles of m.p. 127-128 , undepressed on admixture with the dinitrophenylhydrazone of acetone, m.p. $128^{\circ}$. Ozonolysis thus gave rise to the products levulaldehyde, methylglyoxal, and acetone.

Oxidation with $\mathrm{KMnO}_{4}$. Fraction II (0.430 g.), suspended in water $\left(200 \mathrm{ml}\right.$.), was oxidized by $\mathrm{KMnO}_{4}(1 \cdot 8 \mathrm{~g}$. in $100 \mathrm{ml}$. water) at room temperature. The colour of the $\mathrm{KMnO}_{4}$ eventually disappeared; the $\mathrm{pH}$ of the reaction mixture was $8 \cdot 4$.

Distillation of the total mixture at $\mathbf{1 5} \mathrm{mm}$. into Brady's reagent gave a yellow precipitate which recrystallization showed to be the dinitrophenylhydrazone of acetone, m.p. 128 . (Found: $\mathrm{C}, 45 \cdot 6 ; \mathrm{H}, 4 \cdot 2 ; \mathrm{N}, 22 \cdot 8$. Calc. for $\mathrm{C}_{9} \mathrm{H}_{10} \mathrm{O}_{4} \mathrm{~N}_{4}$ : $\mathrm{C}, 45 \cdot 4 ; \mathrm{H}, 4 \cdot 2 ; \mathrm{N}, 23.5 \%$.) The reaction mixture was then filtered and acidified with $\mathrm{H}_{2} \mathrm{SO}_{4}$ and the volatile acid was distilled off in vacuo, and converted to the $p$-bromophenacyl ester which had m.p. 84-85 $5^{\circ}$ not depressed by authentic $p$ bromophenacyl acetate.

The colourless aqueous concentrate remaining after removal of the acetic acid was exhaustively extracted with ether. The extract was an oil containing a few crystals of oxalic acid. The oxalic acid was removed by dissolution of the oil in water and precipitation as calcium oxalate; the oil was recovered by ether extraction. The non-volatile acid present was converted to the $p$-bromophenacyl ester. The m.p. of the crude ester ( $35 \mathrm{mg}$.) was $130-140^{\circ}$, it was raised to $158-159^{\circ}$ by recrystallization from light petroleum. (Found: $\mathrm{C}, 48 \cdot 0 ; \mathrm{H}, 4 \cdot 0 ; \mathrm{Br}, 26 \cdot 2 . \mathrm{C}_{12} \mathrm{H}_{13} \mathrm{O}_{4} \mathrm{Br}$ requires $\mathrm{C}$, $47 \cdot 8 ; \mathrm{H}, 4.4 ; \mathrm{Br}, 26.6 \%$.) The m.p. was not depressed on admixture with authentic $p$-bromophenacyl $\alpha$-hydroxyisobutyrate, m.p. $158-159^{\circ}$.

Oxidation with $\mathrm{KMnO}_{4}-\mathrm{CrO}_{3}$. Fraction II (0.507 g.) suspended in water $\left(30 \mathrm{ml}\right.$.) was oxidized by $\mathrm{KMnO}_{4}$ (1 g., $10 \mathrm{ml}$. water), $\mathrm{CrO}_{3}\left(0 \cdot 6 \mathrm{~g}\right.$.) and aqueous $\mathrm{H}_{2} \mathrm{SO}_{4}(1 \mathrm{ml}$. conc. acid in $10 \mathrm{ml}$. of solution), by heating on a water bath $(1 \mathrm{hr}$.$) . Volatile oxidation products were removed by$ vacuum evaporation. The chromium, after reduction to the green chromous salt by $\mathrm{NaHSO}_{3}$, was removed by precipitation with excess aqueous $\mathrm{Na}_{2} \mathrm{CO}_{3}$, finally at $100^{\circ}$. The acidified aqueous residue was subjected to continuous ether extraction. The extract gave a 2:4-dinitrophenylhydrazone $(0.23 \mathrm{~g}$.) which, on recrystallization, formed orange needles of m.p. 203-204 ${ }^{\circ}$, soluble in aqueous $\mathrm{NaHCO}_{3}$ and giving no depression in m.p. on admixture with the 2:4-dinitrophenylhydrazone of levulic acid, m.p. 203-204 .

The products of ozonolysis of fraction II, namely methyl. glyoxal, levulaldehyde and acetone are recorded by Pummerer, Matthaus \& Socias-Viñals (1936) as ozonization products of methylheptenone under similar conditions. These workers detected methylglyoxal only when excess of ozone was used.

Oxidation of fraction II with cold aqueous $\mathrm{KMnO}_{4}$ gave rise to acetone, acetic acid, oxalic acid and $\alpha$-hydroxyisobutyric acid. The last-named acid, which does not appear to have been previously recorded as an oxidation product of methylheptenone, no doubt arises by further oxidation of . the 2-methylheptane-2:3-diol-6-one, which was found by Harries (1902) to be the primary oxidation product of methylheptenone by $2 \% \mathrm{KMnO}_{4}$.

The hot oxidation of fraction II with $\mathrm{KMnO}_{4}-\mathrm{CrO}_{3}$ according to the method of Tiemann \& Semmler (1895) produced levulic acid, as recorded by these authors for methylheptenone.

\section{Preparation of methylheptenol}

Racemic 2-methylhept-2-en-6-ol was prepared by reduction of methylheptenone by $\mathrm{Na}$ in ethanol according to Rupe \& Schlocoff (1905). The allophanate obtained from it had m.p. 103-104 ${ }^{\circ}$. Doeuvre (1929) records the m.p. as 99-100 ${ }^{\circ}$. (Found: C, 55.9; H, 8.5; N, 13.0. Calc. for $\mathrm{C}_{10} \mathrm{H}_{18} \mathrm{O}_{3} \mathrm{~N}_{2}: \mathrm{C}, 56 \cdot 0 ; \mathrm{H}, 8.5 ; \mathrm{N}, 13 \cdot 1 \%$.) 
Resolution of racemic methylheptenol. This was achieved by crystallization of the brucine salt of the acid phthalate prepared from the methylheptenol, following the method of Levene \& Haller (1929). The acid phthalate $(67 \cdot 3 \mathrm{~g}$.) gave $35 \mathrm{~g}$. of recrystallized brucine salt $[\alpha]_{5461}^{20^{\circ}}-4 \cdot 26^{\circ}$ in ethanol $(c, 7 \cdot 8)$. This salt was reconverted to the acid phthalate, which was steam distilled with $\mathrm{NaOH}$, giving $5.5 \mathrm{~g}$. of (+)-methylheptenol, $[\alpha]_{5461}^{20^{\circ}}+19 \cdot 1^{\circ}$. This, from its degradation by Levene \& Haller (1929) to the dextrorotatory Llactic acid, is the L-methylheptenol.

Allophanate. The allophanate of the L-methylheptenol had m.p. $137^{\circ},[\alpha]_{5790}^{21^{\circ}}+41^{\circ},[\alpha]_{5461}^{21^{\circ}}+47^{\circ}$ in ethanol $(c, 1 \cdot 06)$. (Found: $\mathrm{C}, 56.2 ; \mathrm{H}, 8.3 ; \mathrm{N}, 13.3 ; \mathrm{C}_{10} \mathrm{H}_{18} \mathrm{O}_{3} \mathrm{~N}_{2}$ requires $\mathrm{C}$, $56 \cdot 0 ; \mathrm{H}, 8 \cdot 5 ; \mathrm{N}, 13 \cdot 1 \%$.)

The possibility was considered that methylheptenone and DL-methylheptenol might be artifacts formed by oxidation and racemization respectively of L-methylheptenol during the distillation process and not true metabolic products.

A sample of synthetic L-methylheptenol was heated at $200^{\circ}$ for $30 \mathrm{~min}$. and then distilled. These conditions are more drastic than those adopted in the fractionation of the metabolic products. During the heating a slight yellow colour developed, but the rotation of the colourless distillate $\left(+7 \cdot 89^{\circ}\right)$ barely differed from that of the original material $\left(+7.92^{\circ}\right)$ measured under the same conditions. The difference is scarcely outside the limits of experimental error. Furthermore, the distillate gave no reaction with Brady's reagent, indicating the absence of appreciable amounts of methylheptenone. Thus all the products identified are genuine metabolic products of the fungus.

\section{Products from ENDOCONIDIOPHORA VIRESCENS}

The development of mycelium was somewhat slower than in the previous species and completely covered the medium after 6-7 days. The upper surface was dark grey (not mottled) with occasional dark-green areas. The reverse was black. Towards the end of the incubation period the odour was marked, but not of the same intensity nor as ester-like as that given by $E$. coerulescens.

Steam-volatile metabolic products. The distillation of the ether extract from the steam distillate gave only one fraction (fraction II) of approximately constant boiling point, corresponding to the higher boiling fraction from $E$. coerulescens. Fraction I, 0.94 g., b.p. 50-165 $/ 767 \mathrm{~mm}$. Fraction II, 3.00 g., b.p. $172-173^{\circ} / 767 \mathrm{~mm}$.

During the collection of fraction $I$ the temperature rose continuously. No indication was obtained of any isobutyl acetate produced by $E$. virescens. Both fractions gave precipitates with Brady's reagent; fraction II gave the same 2:4-dinitrophenylhydrazone and allophanates as those obtained from $E$. coerulescens, but the amounts showed considerable differences. An estimate of the amount of methylheptenone in the distillate was obtained from the amount of 2:4-dinitrophenylhydrazone formed (on the assumption that precipitation is complete). The amount of L-methylheptenol was estimated from the rotation; the rest of the material was assumed to be DL-methylheptenol. These figures shown in Table 1 give a rough guide to the quantitative relationships of the higher boiling constituents of the two fungi.

Table 1. Relative proportions of the metabolic products in the boiling range of $172-176^{\circ}$ from Endoconidiophora coerulescens and $\mathrm{E}$. virescens

$\begin{array}{lccc}\text { Methyl- } & \text { L-Methyl- } \\ \text { heptenone } & \begin{array}{c}\text { DL-Methyl- } \\ \text { heptenol } \\ \text { (\%) }\end{array} & \begin{array}{c}(\%) \\ \text { (by difference) }\end{array} & (\%) \\ \text { E. coerulescens } & 41 & 17 & 42 \\ \text { E. virescens } & 58 & 5 & 37\end{array}$

\section{PRODUCTS FROM ENDOCONIDIOPHORA FIMBRIATA}

Growth was much slower than in both the preceding species. The mycelium was greyish white with occasional black areas and a light grey reverse. A very faint odour could be detected through the cotton-wool plug, but this bore no resemblance to that previously encountered. Only a trace of steam-volatile products was obtained and this gave no characteristic dinitrophenylhydrazone or reaction for carboxylic esters.

\section{SUMMARY}

1. Endoconidiophora coerulescens Münch when grown on a liquid malt medium afforded the volatile metabolic products isobutyl acetate, 2-methylhept2-en-6-one, and a mixture of L- and DL-2-methylhept2-en-6-ol.

2. Under similar conditions, $E$. virescens Davidson produced the same methylheptenone and mixture of L- and DL-methylheptenol as $E$. coerulescens, but in different proportions. No isobutyl acetate was detected in this case.

3. No identifiable volatile metabolic products were obtained from $E$. fimbriata (Ell. \& Hals.) Davidson grown under the same conditions.

4. The products identified are responsible for the odours of the fungi in culture.

\section{REFERENCES}

Akamatsu, S. (1923). Biochem. Z. 142, 188.

Allen, C. F. H. (1930). J. Amer. chem. Soc. 52, 2955.

Badcock, E. C. (1941). Trans. Brit. mycol. Soc. 25, 200.

Birkinshaw, J. H., Bracken, A. \& Findlay, W. P. K. (1944). Biochem. J. 38, 131.

Birkinshaw, J. H., Charles, J. H. V. \& Raistrick, H. (1931). Philos. Trans. B, 220, 355.

Birkinshaw, J. H. \& Findlay, W. P. K. (1940). Biochem. J. 34, 82.

Bohnsack, H. (1943). Ber. dtsch. chem. Ges. 76, 564.

Brady, O. L. \& Elsmie, G. V. (1926). Analyst, 51, 77.

Davidson, R. W. (1944). Mycologia, 36, 300.

Doeuvre, J. (1929). Bull. Soc. chim., Paris, 45, 351.

Harries, C. (1902). Ber. dtsch. chem. Ges. 35, 1179.
Hey, D. H. \& Morris, D. S. (1948). J. chem. Soc. p. 48.

Köbig, J. (1879). Liebigs Ann. 195, 92.

Levene, P. A. \& Haller, H. L. (1929). J. biol. Chem. 83, 177.

Morgan, E. N. (1948). Biochem. J. 43, xxxvii.

Neuberg, C. \& Lewite, A. (1918). Biochem. Z. 91, 257.

Neuberg, C. \& Nord, F. F. (1919). Ber. dtsch. chem. Ges. 52, 2237.

Pummerer, R., Matthaus, G. \& Socias-Viñals, L. (1936). Ber. dtsch. chem. Ges. 69, 170.

Rujpe, H. \& Schlocoff, P. (1905). Ber. dtsch. chem. Ges. 38, 1498.

Schimmel\& Co. (1908). Ber. Schimmel u. Co. Lpz. Nov. p. 84. Tiemann, F. \& Semmler, F. W. (1895). Ber. dtsch. chem. Ges. 28, 2126 . 